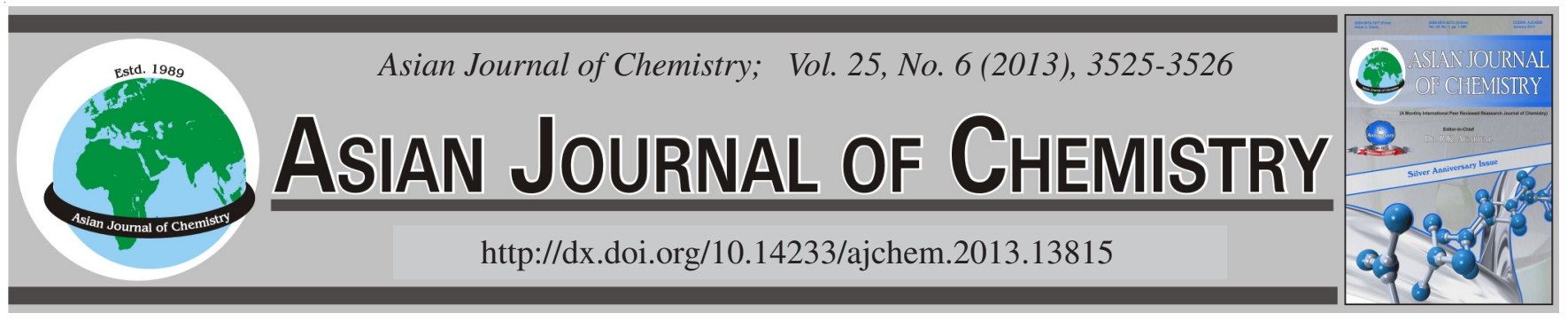

NOTE

\title{
Evaluation of Amino Acid and Vitamin B2 and E Composition of Genetically Modified Antidwarf Mosaic Maize by Automatic Amino acid Analyzer and HPLC
}

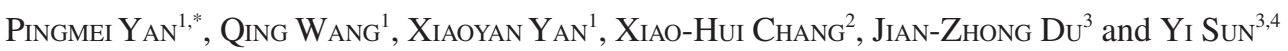

${ }^{1}$ Taiyuan Normal University, Taiyuan 030012, Shanxi Province, P.R. China

${ }^{2}$ Beijing Entry-Exit Inspection and Quarantine Bureau, Beijing 100026, P.R. China

${ }^{3}$ Biotechnology Research Center, Shanxi Academy of Agricultural Sciences, 59 Rd. S. Wucheng, Taiyuan 030031, Shanxi Province, P.R. China ${ }^{4}$ Key Laboratory of Crop Gene Resources and Germplasm Enhancement on Loess Plateau, Ministy of Agriculture, Taiyuan 030031, P.R. China

*Corresponding author: E-mail: yanpingmei2010@gmail.com

\begin{abstract}
The nutrition assessment of transgenic food is an important part of safety evaluation. The amino acids and vitamins composition of genetically modified antidwarf mosaic maize were comprehensively evaluated to assess the safety assessment of transgenic food. The results showed that the most components of transgenic corn had no significant difference from those of non-transgenic, which proved that genetically modified antidwarf mosaic maize is safe. But the contents of vitamin $\mathrm{E}$ and three amino acids in transgenic corn had significant difference from its parent variety, so genetically modified crops must undergo a rigorous safety test before as a food.
\end{abstract}

Key Words: Amino acid, Vitamin, Genetically modified Antidwarf mosaic maize, Automatic amino acid analyzer, HPLC.

Transgenic technology plays an important role in increasing food production, improving nutrition and food processing and storage characteristics ${ }^{1}$. At the same time, the safety of the genetically modified foods are widely recognized ${ }^{2}$ and nutrition assessment is an important part of safety evaluation ${ }^{3}$. But the nutrition change of transgenic food was paid less attention.

Corn, as one of the world's most important food crops, is the important raw material of modern industry, food, pharmaceutical and chemical fields. Genetically modified antidwarf mosaic maize is an important technical means for resistance to mosaic virus, but the nutritional structure and chemical composition of genetically modified is still unclear. In this study, the amino acids and vitamins composition of genetically modified antidwarf mosaic maize and its original parents of non-genetically modified corn were comprehensively evaluated, which provides the basis for safety assessment of transgenic corn.

Genetically modified maize dwarf mosaic resistance and non-genetically modified maize were gifted by Professor Sun Yi of Shanxi Agricultural Biotechnology Research Center, two cultivars were grown under the same conditions and management. Sampling by the five-point sampling method after maturity, dry at natural conditions, smash, screening through 40 mesh sieve, save in the vacuum bag. Three repeated measurements for each sample.
Methods: Detection of amino acid content referred to GB/ T5009.124-2003 $(\mathrm{g} / 100 \mathrm{~g})$. Detection of vitamin Bl referred to $\mathrm{GB} / \mathrm{T} 5009.84-2003^{5}$ (g/100 g). Detection of vitamin B2 referred to GB/T $5009.85-2003^{6}(\mathrm{~g} / 100 \mathrm{~g})$ and detection of vitamin E referred to GB/T 5009.84-2003 ${ }^{5}$ (g/100 g).

Statistical analysis of data: The data were analyzed by SPSS11.0 software $t$-test.

Comparison of amino acid composition of genetically modified maize and non-genetically modified maize: Amino acid composition of genetically modified maize and nongenetically modified maize were showed in Table-1. Compared with the non-genetically modified maize, in genetically modified corn, glycine and valine were significantly lower than non-genetically modified maize, the other 16 kinds of amino acid had no significant difference. Only valine as the essential amino acid had significant difference, the other seven kinds of essential amino acids had no significant difference.

Composition of vitamin: Vitamins composition in transgenic and non-transgenic corn is shown in Table-2. The results showed that contents of vitamin B1 and vitamin B2 in genetically modified corn had no significant difference from those in non-genetically modified corn; but the content of vitamin $\mathrm{E}$ in genetically modified corn was significantly lower than that in non-genetically modified corn $(p<0.05)$. 


\begin{tabular}{ccc}
\hline \multicolumn{3}{c}{ TABLE-1 } \\
COMPOSITIONAL ANALYSIS OF AMINO \\
ACIDS $(\mathrm{mg} / 100 \mathrm{~g}$ DRY MASS $)(\mathrm{n}=3)$ \\
\hline Amino acid & $\begin{array}{c}\text { Non-transgenic } \\
\text { corn }(\mathrm{g} / 100 \mathrm{~g})\end{array}$ & $\begin{array}{c}\text { Transgenic corn } \\
(\mathrm{g} / 100 \mathrm{~g})\end{array}$ \\
\hline ASP & $0.7267 \pm 0.0451$ & $0.6360 \pm 0.0251$ \\
THR & $0.4500 \pm 0.0400$ & $0.3800 \pm 0.0400$ \\
SER & $0.4000 \pm 0.0200$ & $0.3400 \pm 0.0300$ \\
GLN & $2.0533 \pm 0.1301$ & $1.9460 \pm 0.3208$ \\
PRO & $0.5333 \pm 0.0451$ & $0.6130 \pm 0.0702$ \\
GLY & $0.4133 \pm 0.0513$ & $0.1320 \pm 0.1715$ \\
ALA & $0.2727 \pm 0.3528$ & $0.2500 \pm 0.3200$ \\
CYS & $0.0743 \pm 0.0055$ & $0.0803 \pm 0.0055$ \\
VAL & $0.2127 \pm 0.2749$ & $0.0477 \pm 0.0056$ \\
MET & $0.0807 \pm 0.0170$ & $0.0640 \pm 0.0087$ \\
ILE & $0.3600 \pm 0.0557$ & $0.2766 \pm 0.0404$ \\
LEU & $1.2133 \pm 0.2802$ & $1.1900 \pm 0.0916$ \\
TYR & $0.1167 \pm 0.0306$ & $0.1413 \pm 0.0480$ \\
PHE & $0.5100 \pm 0.0300$ & $0.3766 \pm 0.0480$ \\
LYS & $0.3300 \pm 0.0400$ & $0.3100 \pm 0.0754$ \\
Trp & $0.3633 \pm 0.0710$ & $0.3800 \pm 0.0360$ \\
HIS & $0.2600 \pm 0.0557$ & $0.2033 \pm 0.0153$ \\
ARG & $0.4067 \pm 0.0351$ & $0.3533 \pm 0.0251$ \\
AR & $0.8114 \pm 1.0063$ & $0.7722 \pm 1.0356$ \\
\hline
\end{tabular}

\begin{tabular}{|c|c|c|}
\hline \multicolumn{3}{|c|}{$\begin{array}{c}\text { TABLE- } 2 \\
\text { MINERALS AND PHYTATE PHOSPHOROUS } \\
\text { ANALYSES OF THE MAIZE }\end{array}$} \\
\hline Vitamin & $\begin{array}{l}\text { Non-transgenic corn } \\
(\mathrm{g} / 100 \mathrm{~g})\end{array}$ & $\begin{array}{l}\text { Transgenic corn } \\
(\mathrm{g} / 100 \mathrm{~g})\end{array}$ \\
\hline Vitamin B1 (mg/kg) & $8.69 \pm 0.24$ & $8.71 \pm 0.35$ \\
\hline Vitamin B2 $(\mathrm{mg} / \mathrm{kg})$ & $1.29 \pm 0.47$ & $1.28 \pm 0.37$ \\
\hline Vitamin E (mg/kg) & $4.12 \pm 0.41$ & $6.21 \pm 0.44$ \\
\hline
\end{tabular}

At present, the safety evaluation of genetically modified foods follow the principle of substantial equivalence in the world, which is the key steps in the process of genetically modified food safety evaluation ${ }^{7}$. The so-called "substantial equivalence" principle, mainly refers to compare the types and compositions of the major nutrients in genetically modified foods, the main nutritional antagonistic substances, toxic substances and allergic substances with non-transgenic parent foods. If there is no significant difference, we believe the transgenic foods is safe ${ }^{8}$.

Vitamins are essential and important nutrients for the body ${ }^{9}$. This study proved that vitamin B1 and vitamin B2 in genetically modified corn had no significant difference from non-genetically modified corn; vitamin $\mathrm{E}$ in genetically modified corn was significantly lower. Amino acids are the basic substance to build proteins. Although most amino acids have no significant difference, glycine and valine were significantly lower than non-genetically modified maize.

The data from this study showed that the most components of transgenic corn have no significant difference from those of non-transgenic, which proved that genetically modified antidwarf mosaic maize is safe. But the contents of vitamin $\mathrm{E}$ and three amino acids in transgenic corn had significant difference from its parent variety, so genetically modified crops must undergo a rigorous safety test before as a food.

\section{ACKNOWLEDGEMENTS}

This work was supported by Agricultural and Social Science and Technology Project of Shanxi Province (20100312004) and National major project for Breeding New GeneticallyModified Organism Varieties (2009zx08003).

\section{REFERENCES}

1. C.Q. Yang, L.J. Wang, Y.B. Mao and X.Y. Chen, Chin Bull. Life Sci., 23, 140 (2011).

2. A. König, A. Cockburn, R.W.R. Crevel, E. Debruyne, R. Grafstroem, U. Hammerling, I. Kimber, I. Knudsen, H.A. Kuiper, A.A.C.M. Peijnenburg, A.H. Penninks, M. Poulsen, M. Schauzu and J.M. Wal, Food Chem. Toxicol., 42, 1047 (2004).

3. G.K. Flachowsky, H. Aulrich, Böhme and I. Halle, Animal Feed Sci. Technol., 133, 2 (2007).

4. National Standards of P. R. China: GB/T5009.124-2003.

5. National Standards of P. R. China: GB/T 5009.84-2003.

6. National Standards of P. R. China: GB/T 5009.85-2003.

7. B.M. Chassy, Regul. Toxicol. Pharmacol., 58, S62 (2010).

8. J.M. Baker, N.D. Hawkins, J.L. Ward, A. Lovegrove, A. Napier, P.R. Shewry and M.H. Beale, Plant Biotechnol. J., 4, 381 (2006).

9. A.T. Vasilaki, D. Talwar, J. Kinsella, A. Duncan, D. O'Reilly and D.C. McMillan, Clin. Nutr. Supplem., 4, 159 (2009). 